\title{
List of authors (in alphabetical order)
}

\section{https://doi.org/10.17234/9789531758314.11}

\section{Dominik, Petra}

University of Zadar, Postgraduate Doctoral Study, Programme in Humanities

\section{Erdeljac, Vlasta}

University of Zagreb, Faculty of Humanities and Social Sciences, Department of Linguistics

\section{Filipović Đurđević, Dušica}

University of Belgrade, Faculty of Philosophy, Department of Psychology and University of Novi Sad, Faculty of Philosophy, Laboratory for Experimental Psychology

Kircher, Tilo Philipps University Marburg, Department of Psychiatry and Psychotherapy

\section{Kužina, Iva}

University of Zagreb, Faculty of Humanities and Social Sciences, Department of Linguistics

\section{Mimica, Ninoslav}

University of Zagreb, School of Medicine, Chair of Psychiatry and Psychological Medicine and University Psychiatric Hospital Vrapče

Nagels, Arne Johannes Gutenberg University Mainz, Department of English and Linguistics, General Linguistics

\section{Ostojić, Draženka}

University of Zagreb, Faculty of Law, Social Work Study Centre and University Psychiatric Hospital Vrapče

\section{Perovic, Alexandra}

University College London, UK, Division of Psychology and Language Sciences, Department of Linguistics

\section{Popović Stijačić, Milica}

University of Novi Sad, Faculty of Philosophy, Laboratory for Experimental Psychology and University of Belgrade, Faculty of Philosophy, Laboratory for Experimental Psychology

\section{Rosenkranz, Anna}

University of Cologne, Faculty of Human Sciences, Department of Special Education and Rehabilitation 


\section{Savić, Aleksandar}

University of Zagreb, School of Medicine, Chair of Psychiatry and Psychological Medicine and University Psychiatric Hospital Vrapče

\section{Sekulić Sović, Martina}

University of Zagreb, Faculty of Humanities and Social Sciences, Department of Linguistics

\section{Vandek, Mija}

University of Zagreb, Faculty of Humanities and Social Sciences, Department of Linguistics

\section{Wexler, Ken}

Massachusetts Institute of Technology, USA, Department of Brain and Cognitive Sciences, Department of Linguistics

\section{List of reviewers (in alphabetical order)}

\section{Bertoša, Mislava}

University of Zagreb, Faculty of Humanities and Social Sciences, Department of Linguistics

Bratinć, Maja Institute of Croatian Language and Linguistics

\section{Cepanec, Maja}

University of Zagreb, Faculty of Education and Rehabilitation Sciences, Department of Speech and Language Pathology

Havelka, Jelena

University of Leeds, School of Psychology

\section{Horga, Damir}

University of Zagreb, Faculty of Humanities and Social Sciences, Department of Phonetics

\section{Karlović, Dalibor}

Catholic University of Croatia, Department of Psychology

University Clinical Hospital Center Sestre Milosrdnice, Department of Psychiatry

Kotrla Topić, Marina

Institute of Social Sciences Ivo Pilar

\section{Manouilidou, Christina}

University of Ljubljana, Department of Comparative and General Linguistics

Martínez-Ferreiro, Silvia

University of Copenhagen, Nordic Studies and Linguistics

\section{Mildner, Vesna}

University of Zagreb, Faculty of Humanities and Social Sciences, Department of Phonetics 


\section{Rojnić Kuzman, Martina}

University of Zagreb, School of Medicine, Chair of Psychiatry and Psychological Medicine

University Hospital Centre Zagreb, Department of Psychiatry

Šakić Velić, Marija

Institute of Social Sciences Ivo Pilar

Catholic University of Croatia, Department of Psychology

Willer-Gold, Jana (Editor-in-chief)

University College London, UK, Division of Psychology and Language Sciences, Department of Linguistics

Alexander D. Hoyt, copy editor

University of Zagreb, Faculty of Humanities and Social Sciences,

Department of English 